\title{
Comparison Of The Linear And The Non-linear Block Adjustment On Satellite Images Research
}

\author{
Canhai $\mathrm{Li}^{1}$, Chen Chen ${ }^{1}$, Zhengsheng Guo ${ }^{1,2}$, Qian Liu ${ }^{1}$ \\ ${ }^{1}$ Satellite Surveying and Mapping Application Center, National Administration of Surveying, Mapping and Geoinformation, No.1 \\ Baishengcun, Zizhuyuan Road, Haidian District,100048 Beijing, P.R. China - ( lich, chenc)@ sasmac.cn \\ ${ }^{2}$ Dept. of Geomatics, Liaoning Technical University, Fuxin 123000, Liaoning, China - guo_shzh@163.com
}

KEY WORDS: Linear Least square method, Non-Linear Least square method, error equation, Block adjustment, Rational Function Model, High-resolution Satellite images

\begin{abstract}
:
The Rational Function Model (RFM) is a non-linear model. Usually, the RFM-based satellite image block adjustment uses the Taylor series to expand error equations, and then solves the linear model. Theoretically, linearization of a non-linear model affects the accuracy and reliability of the adjustment result. This paper presents linear and non-linear methods for solving the RFM-based block adjustment,and takes ZiYuan3(ZY-3) satellite imagery block adjustment as an example, using same check points to assess the accuracy of the two methods. In this paper, a non-linear least square method is used for solving the RFM-based block adjustment, which expands a solution to the block adjustment.
\end{abstract}

\section{Introduction}

Rational function model (RFM) is a general geometric model used by most remote sensing satellites nowadays. RFM is a high precision approximation to a rigorous imaging geometry model. It can be applied to any space sensor platform.

The RFM-based satellite image block adjustment uses the Taylor series to expand error equations, and then solves the linear model. , and a two-dimensional affine transformation for the compensation of imagery has been applied in most previous researches. RFM is one of non-linear models and the accuracy and reliability of the RFM-based block adjustment are effected by expanding an error equation into a linear model in theory.

In this article, a linear least square method and a non-linear least square method for the RFM-based block adjustment are described. This paper mainly focuses on the non-linear least square method for the RFM-based block adjustment. A nonlinear least square regression can be used to solve the error equation through a residual equation which is based on ground control points. Levenberg-Marquardt (LM) algorithm with gradient descent computation is aimed to get the best solution.

In addition, the block adjustment of ZY-3 satellite imagery is used as an example to state the solution of the linear and the non-linear block adjustment. The linear and the non-linear block adjustment are presented under same ground control points. The accuracy result and advantage of comparison between the linear and the non-linear method through public check points will be presented.

In this paper, the solution of block adjustment of satellite images proceeded by the non-linear block adjustment is given, which expands the data processing method on the block adjustment of satellite images.

\section{Rational function model}

Rational Function Model(RFM) is a kind of universal sensor model. Its essence is to describe and replace the rigorous imaging process more closely through a more complex mathematical model. A direct correspondence between the object space coordinates and the coordinates of the image points is established. The RFM model generally uses the RPC parameter (Rational Polynomial Coefficients) to represent. The RPC parameter generally has 80 coefficients. As an alternative to a physical camera model, the rational function describes the transformation between the image and object spaces. The rational function transforms a point in the object space $(\mathrm{P}, \mathrm{L}, \mathrm{H})$ into its corresponding image point $(\mathrm{C}, \mathrm{R})$ through a ratio of the two polynomials shown in Equation (1):

$$
\left\{\begin{array}{l}
C_{n}=\frac{F_{1}\left(P_{n}, L_{n}, H_{n}\right)}{F_{2}\left(P_{n}, L_{n}, H_{n}\right)} \\
R_{n}=\frac{F_{3}\left(P_{n}, L_{n}, H_{n}\right)}{F_{4}\left(P_{n}, L_{n}, H_{n}\right)}
\end{array}\right.
$$

where $C_{n}, R_{n}=$ normalized image-space coordinates $\mathrm{L}_{\mathrm{n}}, \mathrm{P}_{\mathrm{n}}, \mathrm{H}_{\mathrm{n}}=$ normalized object-space coordinates

Given the object-space coordinates $(\mathrm{P}, \mathrm{L}, \mathrm{H})$, where $\mathrm{P}$ is geodetic latitude, $\mathrm{L}$ is geodetic longitude, and $\mathrm{H}$ is height above the ellipsoid, and the latitude, longitude, and height offsets and scale factors (LAT_OFF, LONG_OFF, HEIGHT_OFF, with LAT_SCALE, LONG_SCALE, HEIGHT_SCALE), the calculation of image-space coordinates begins by normalizing latitude, longitude, and height as follows:

$$
\begin{aligned}
& \mathrm{P}_{\mathrm{n}}=\frac{\mathrm{P}-\mathrm{LAT}_{-} \mathrm{OFF}}{\mathrm{LAT}_{-} \mathrm{SCALE}} \\
& \mathrm{L}_{\mathrm{n}}=\frac{\mathrm{L}-\mathrm{LONG}_{-} \mathrm{OFF}}{\mathrm{LONG} \text { SCALE }}
\end{aligned}
$$




$$
\mathrm{H}_{\mathrm{n}}=\frac{\mathrm{H}-\mathrm{HEIGHT} \text { OFF }}{\text { HEIGHT_SCALE }}
$$

Using line and sample offsets and scale factors(LINE_OFF, SAMP_OFF, LINE_SCALE, SAMP_SCALE), the denormalized image-space coordinates $(\mathrm{C}, \mathrm{R})$, where Line is the image line number expressed in pixels with pixel zero as the center of the first line, and Sample is the sample number expressed in pixels with pixel zero is the center of the left-most sample, are finally computed as:

$$
\begin{aligned}
& \mathrm{C}=\mathrm{c} \times \text { SAMP_SCALE }+\mathrm{SAMP}_{-} \text {OFF } \\
& \mathrm{R}=\mathrm{r} \times \text { LINE_SCALE }+ \text { LINE_OFF }
\end{aligned}
$$

where the polynomial $\mathrm{F}_{\mathrm{i}}(\mathrm{i}=1,2,3$, and 4$)$ has the following general form:

$$
\begin{aligned}
\mathrm{F}_{\mathrm{i}}=\mathrm{a}_{1} & +\mathrm{a}_{2} \mathrm{~L}_{\mathrm{n}}+\mathrm{a}_{3} \mathrm{P}_{\mathrm{n}}+\mathrm{a}_{4} \mathrm{H}_{\mathrm{n}}+\mathrm{a}_{5} \mathrm{~L}_{\mathrm{n}} \mathrm{P}_{\mathrm{n}} \\
& +\mathrm{a}_{6} \mathrm{~L}_{\mathrm{n}} \mathrm{H}_{\mathrm{n}}+\mathrm{a}_{7} \mathrm{P}_{\mathrm{n}} \mathrm{H}_{\mathrm{n}}+\mathrm{a}_{8} \mathrm{~L}_{\mathrm{n}}^{2}+\mathrm{a}_{9} \mathrm{P}_{\mathrm{n}}^{2} \\
& +\mathrm{a}_{10} \mathrm{H}_{\mathrm{n}}^{2}+\mathrm{a}_{11} \mathrm{~L}_{\mathrm{n}} \mathrm{P}_{\mathrm{n}} \mathrm{H}_{\mathrm{n}}+\mathrm{a}_{12} \mathrm{~L}_{\mathrm{n}}^{3} \\
& +\mathrm{a}_{13} \mathrm{~L}_{\mathrm{n}} \mathrm{P}_{\mathrm{n}}^{2}+\mathrm{a}_{14} \mathrm{~L}_{\mathrm{n}} \mathrm{H}_{\mathrm{n}}^{2}+\mathrm{a}_{15} \mathrm{~L}_{\mathrm{n}}^{2} \mathrm{P}_{\mathrm{n}} \\
& +\mathrm{a}_{16} \mathrm{P}_{\mathrm{n}}^{3}+\mathrm{a}_{17} \mathrm{P}_{\mathrm{n}} \mathrm{H}_{\mathrm{n}}^{2}+\mathrm{a}_{18} \mathrm{~L}_{\mathrm{n}}^{2} \mathrm{H}_{\mathrm{n}} \\
& +\mathrm{a}_{19} \mathrm{P}_{\mathrm{n}}^{2} \mathrm{H}_{\mathrm{n}}+\mathrm{a}_{20} \mathrm{H}_{\mathrm{n}}^{3}
\end{aligned}
$$

The maximum power of each of the coordinates of each item in the polynomial of formula (1) is not more than 3 . The sum of the power of each item of each coordinate is not more than 3 (There are usually 1, 2, and 3 three values).

\section{Block adjustment based on RFM}

Block adjustment is to reduce the number of control points for model parameter calculation, by a few control points on the image model parameters of large area calculation, the second one is to assign errors through the global uniform, realize the small relative error area between images.

General RFM and error compensation parameters are generally used in block adjustment of high resolution satellite images. The use of the image party can also be compensated by the square correction parameters. Using RFM and the affine transformation based on the image square, the model requirements of block adjustment of high resolution satellite images can be met. ground control of block adjustment:

$$
\begin{aligned}
& F_{C}=e_{0}+e_{1} C+e_{2} R-c \\
& F_{R}=f_{0}+f_{1} C+f_{2} R-r
\end{aligned}
$$

where $\mathrm{C}, \mathrm{R}=$ The image coordinates of a ground control point or tie point calculated by a formula (1) image coordinates

$\mathrm{c}, \mathrm{r}=$ The observation value of the image coordinates of a ground control point or tie point

\subsection{Linear Block Adjustment}

The formula (8) is expanded by the Tailor formula to retain the linear term:

$$
\begin{aligned}
\mathrm{C}+\mathrm{v}_{\mathrm{C}} & =\mathrm{C}_{0}+\frac{\partial \mathrm{C}}{\partial \mathrm{P}} \Delta \mathrm{P}+\frac{\partial \mathrm{C}}{\partial \mathrm{L}} \Delta \mathrm{L}+\frac{\partial \mathrm{C}}{\partial \mathrm{H}} \Delta \mathrm{H} \\
& +\frac{\partial \mathrm{C}}{\partial \mathrm{e}_{0}} \Delta \mathrm{e}_{0}+\frac{\partial \mathrm{C}}{\partial \mathrm{e}_{1}} \Delta \mathrm{e}_{1}+\frac{\partial \mathrm{C}}{\partial \mathrm{e}} \Delta \mathrm{e}_{2} \\
\mathrm{R}+\mathrm{v}_{\mathrm{R}} & =\mathrm{R}_{0}+\frac{\partial \mathrm{R}}{\partial \mathrm{P}} \Delta \mathrm{P}+\frac{\partial \mathrm{R}}{\partial \mathrm{L}} \Delta \mathrm{L}+\frac{\partial \mathrm{R}}{\partial \mathrm{H}} \Delta \mathrm{H} \\
& +\frac{\partial \mathrm{R}}{\partial \mathrm{f}_{0}} \Delta \mathrm{f}_{0}+\frac{\partial \mathrm{R}}{\partial \mathrm{f}_{1}} \Delta \mathrm{f}_{1}+\frac{\partial \mathrm{R}}{\partial \mathrm{f}} \Delta \mathrm{f}_{2}
\end{aligned}
$$

Expression in a matrix form:

$$
\begin{aligned}
& \mathrm{V}=\mathrm{AX}+\mathrm{L} \\
& \mathrm{A}=\left(\begin{array}{lllllllll}
\frac{\partial \mathrm{C}}{\partial \mathrm{P}} & \frac{\partial \mathrm{C}}{\partial \mathrm{L}} & \frac{\partial \mathrm{C}}{\partial \mathrm{H}} & \frac{\partial \mathrm{C}}{\partial \mathbf{e}_{0}} & \frac{\partial \mathrm{C}}{\partial \mathbf{e}_{1}} & \frac{\partial \mathrm{C}}{\partial \mathbf{e}_{2}} & 0 & 0 & 0 \\
\frac{\partial \mathrm{R}}{\partial \mathrm{P}} & \frac{\partial \mathrm{R}}{\partial \mathrm{L}} & \frac{\partial \mathrm{R}}{\partial \mathrm{H}} & 0 & 0 & 0 & \frac{\partial \mathrm{R}}{\partial \mathrm{f}_{0}} & \frac{\partial \mathrm{R}}{\partial \mathrm{f}_{1}} & \frac{\partial \mathrm{R}}{\partial \mathrm{f}_{2}} \\
\ldots & \ldots & & & & & & &
\end{array}\right)(11) \\
& \mathrm{X}=\left(\begin{array}{lllllllll}
\Delta \mathrm{P} & \Delta \mathrm{L} & \Delta \mathrm{H} & \Delta \mathrm{e}_{0} & \Delta \mathrm{e}_{1} & \Delta \mathrm{e}_{2} & \Delta \mathrm{f}_{0} & \Delta \mathrm{f}_{1} & \Delta \mathrm{f}_{2}
\end{array}\right)^{\mathrm{T}} \\
& L=\left(\begin{array}{l}
C_{0}-C \\
R_{0}-R
\end{array}\right) \\
& \mathrm{A}=\left(\begin{array}{llllllll}
\frac{\partial \mathrm{C}}{\partial \mathrm{P}} & \frac{\partial \mathrm{C}}{\partial \mathrm{L}} & \frac{\partial \mathrm{C}}{\partial \mathbf{e}_{0}} & \frac{\partial \mathrm{C}}{\partial \mathbf{e}_{1}} & \frac{\partial \mathrm{C}}{\partial \mathbf{e}_{2}} & 0 & 0 & 0 \\
\frac{\partial \mathrm{R}}{\partial \mathrm{P}} & \frac{\partial \mathrm{R}}{\partial \mathrm{L}} & 0 & 0 & 0 & \frac{\partial \mathrm{R}}{\partial \mathrm{f}_{0}} & \frac{\partial \mathrm{R}}{\partial \mathbf{f}_{1}} & \frac{\partial \mathrm{R}}{\partial \mathbf{f}_{2}} \\
\ldots & \ldots & & & & &
\end{array}\right)
\end{aligned}
$$

The error equation is transformed into the normal equation (15). The solution of this equation is obtained by the least squares solution.

$$
d X=\left(A^{T} A\right)^{-1} A^{T} L
$$

\subsection{Non-linear Block Adjustment}

A non-linear least square regression can be used to solve error equation through residual equation which is based on ground control points. We can formulate the block adjustment problem as an incremental maximum likelihood estimation over a set of RPC compensation parameter and undetermined coordinates of tie points, together forming the state $\mathrm{x}=[\mathrm{e}, \mathrm{f}, \mathrm{P}, \mathrm{L}, \mathrm{H}]$. We want to find the optimal configuration satisfying the measurements. The established residual equation with the formula (1) and (8) : 


$$
\begin{aligned}
& \mathrm{f}_{1}(\mathrm{x})=\mathrm{e}_{0}+\mathrm{e}_{1} \frac{\mathrm{F}_{1}(\mathrm{P}, \mathrm{L}, \mathrm{H})}{\mathrm{F}_{2}(\mathrm{P}, \mathrm{L}, \mathrm{H})}+\mathrm{e}_{2} \frac{\mathrm{F}_{3}(\mathrm{P}, \mathrm{L}, \mathrm{H})}{\mathrm{F}_{4}(\mathrm{P}, \mathrm{L}, \mathrm{H})}-\mathrm{c} \\
& \mathrm{f}_{2}(\mathrm{x})=\mathrm{f}_{0}+\mathrm{f}_{1} \frac{\mathrm{F}_{1}(\mathrm{P}, \mathrm{L}, \mathrm{H})}{\mathrm{F}_{2}(\mathrm{P}, \mathrm{L}, \mathrm{H})}+\mathrm{f}_{2} \frac{\mathrm{F}_{3}(\mathrm{P}, \mathrm{L}, \mathrm{H})}{\mathrm{F}_{4}(\mathrm{P}, \mathrm{L}, \mathrm{H})}-\mathrm{r}
\end{aligned}
$$

$$
\mathrm{F}(\mathrm{x})=\left[\begin{array}{c}
\mathrm{f}_{1}\left(\mathrm{x}_{1}\right) \\
\mathrm{f}_{2}\left(\mathrm{x}_{1}\right) \\
\cdot \\
\cdot \\
\cdot \\
\mathrm{f}_{1}\left(\mathrm{x}_{\mathrm{n}}\right) \\
\mathrm{f}_{2}\left(\mathrm{x}_{\mathrm{n}}\right)
\end{array}\right], \quad \mathrm{x}=\left[\begin{array}{c}
\mathrm{x}_{1} \\
\cdot \\
\cdot \\
\cdot \\
\mathrm{x}_{\mathrm{n}}
\end{array}\right], \quad \mathrm{x}_{\mathrm{i}}=\left[\begin{array}{c}
\mathrm{P}_{\mathrm{i}} \\
\mathrm{L}_{\mathrm{i}} \\
\mathrm{H}_{\mathrm{i}} \\
\mathrm{e}_{\mathrm{i} 0} \\
\mathrm{e}_{\mathrm{i} 1} \\
\mathrm{e}_{\mathrm{i} 2} \\
\mathrm{f}_{\mathrm{i} 0} \\
\mathrm{f}_{\mathrm{i} 1} \\
\mathrm{f}_{\mathrm{i} 2}
\end{array}\right] \text { (17) }
$$

$$
\mathrm{F}(\mathbf{x})=0
$$

The ground control points in image $i$ according to the formula (16) established equation $f_{i}(x)=0$. The equation set (18) is nonlinear. Solving the equation set,nonlinear least square is the form of least squares analysis which is used to fit a set of $m$ observations with a model that is non-linear in $n$ unknown parameters $(m>n)$. It is used in some forms of non-linear regression. The basis of the method is to approximate the model by a linear one and to refine the parameters by successive iterations. There are many similarities to linear least squares, but also some significant differences.

A model function $y=f(x, \beta)$, that in addition to the variable $x$ also depends on $\mathrm{n}$ parameters, $\beta=\left(\beta_{1}, \beta_{2}, \cdots, \beta_{n}\right)$. with $\mathrm{m} \geq$ $\mathrm{n}$. It is desired to find the vector $\beta$ of parameters such that the curve fits best the given data in the least squares sense, that is, the sum of squares:

$$
\min _{\mathbf{x}} \frac{1}{2} \sum_{\mathbf{i}} \beta_{\mathbf{i}}\left(\left\|f_{i}\left(\mathbf{x}_{\mathbf{i} 1}, \ldots, \mathbf{x}_{\mathbf{i k}}\right)\right\|^{2}\right)
$$

Levenberg-Marquardt (LM) algorithm can provide numerical solutions for the number of non-linear minimization (local minimum). This algorithm can achieve the advantage of combining Gauss and Newton algorithm and gradient descent algorithm by modifying parameters at execution time. LM algorithm with iterating computation is aimed to get best solution. LM algorithm is calculated based on the Trust Region Method. The radius of reliable range is changing during the progress of the calculation. The change of the reliable range is based on the accuracy of the equation which can be determined through the gain ration. The radius of reliable range and the step size of iteration are controlled by the gain ration in real time. If the percentage of the gain ration is too low, it is indicated the radius of reliable range of the change is far smaller than the value of the model. It means the result is not the ideal one and the radius of reliable range need be reduced. In a converse situation, it is indicated the radius of reliable range of the change is bigger than the value of the model. It shows the residual is sufficiently small and the radius of reliable range can be enlarged to calculate in continue.

LM algorithm can be divided into the following steps:

Step 1) Randomly set the initial weight vector $W_{0}$, set the target error $\varepsilon, k=1$.

Step 2) For the n element equation in the formula(17), we compute the Jacobi matrix $J$ of the weight $w$.

Step 3) Search by press:

$$
\begin{aligned}
& W^{(k+1)}=W^{(k)}-\eta_{k}\left(J^{T}\left(W^{(k)}\right) J^{T} W^{(k)}+\eta_{k} I\right) \\
& \times J^{T}\left(W^{(k)}\right) f\left(W^{(k)}\right)
\end{aligned}
$$

Step 4) If $E\left(W^{(k)}\right) \leq \varepsilon$, then the algorithm terminates.

Gain the weight vector that satisfies the requirement of precision. Otherwise, turn to step 5 .

Step 5) If $\left\|\mathrm{f}\left(W^{(k+1)}\right)-\mathrm{f}\left(W^{(k)}\right)\right\| \leq 0$,is that $\mu_{\mathrm{k}}=\mu_{\mathrm{k} /} / 4$.Otherwise, $\mu_{\mathrm{k}}=\mu_{\mathrm{k}} \times 4$, turn to step 3 .

\section{Experiment and analysis}

\subsection{Experimental data}

In this paper, ZY-3 satellite images in Tianjin area are used as experimental data. Contains 11 view images and RPC parameters in Figure 1. Experimentation area reference data is a high resolution DOM. Elevation is obtained through 1:50000 DEM interpolation. 


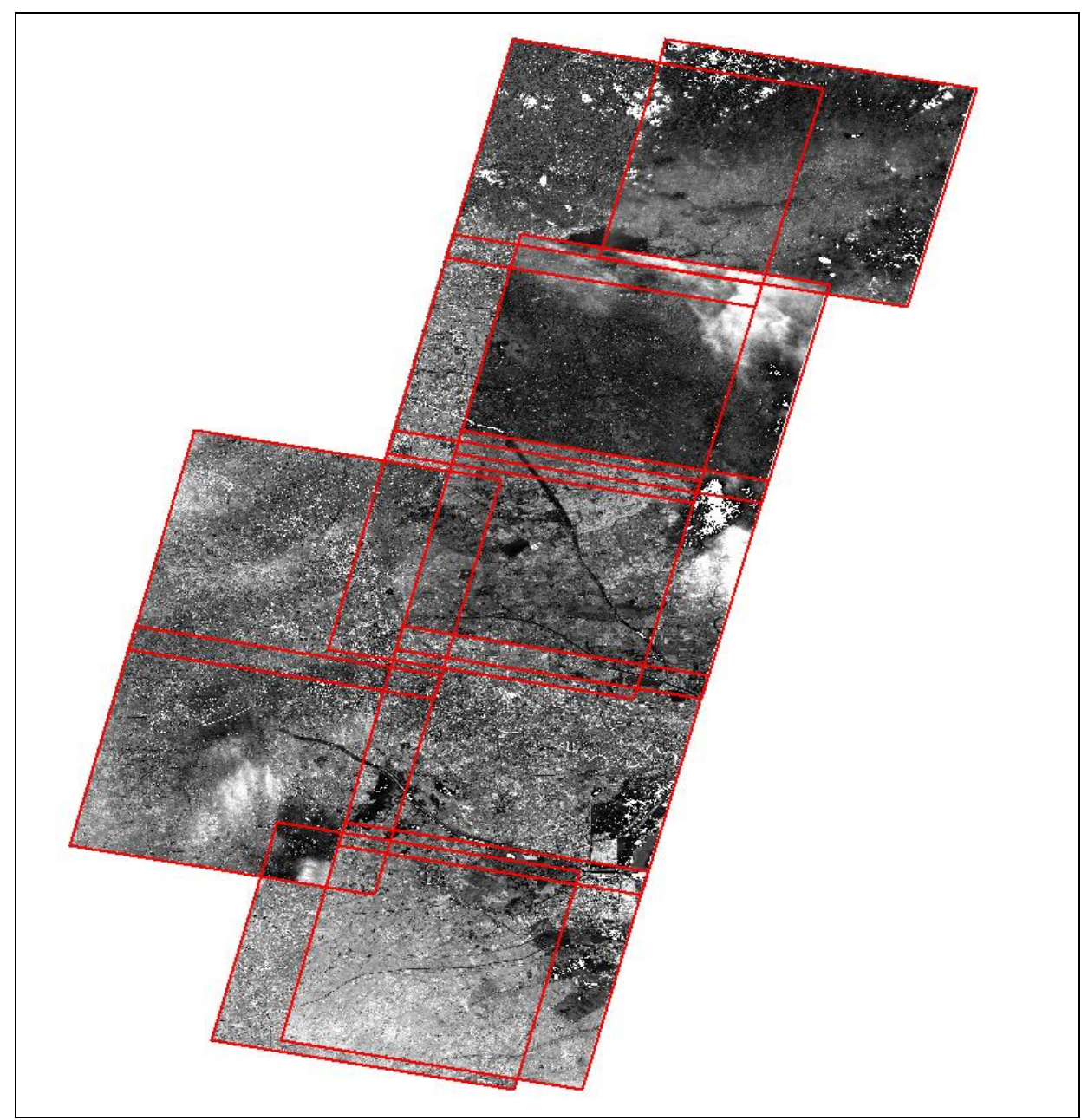

Figure 1. Image layout

\subsection{Experimental scheme}

All the ground control points measured on the images are all obvious objects spot. The ground control points are selected from the high-precision image data by manual method. The image coordinates are selected on the left image. Accordingly, the corresponding object coordinates on the right image are selected. The control image of the right image is as 1:10000 mapping in Figure 2.

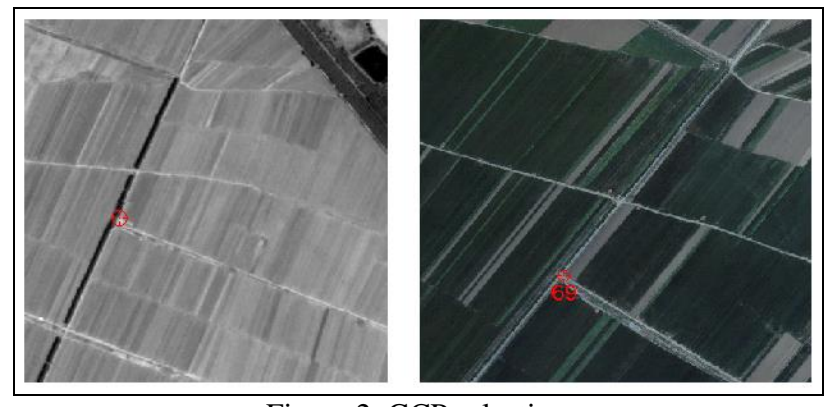

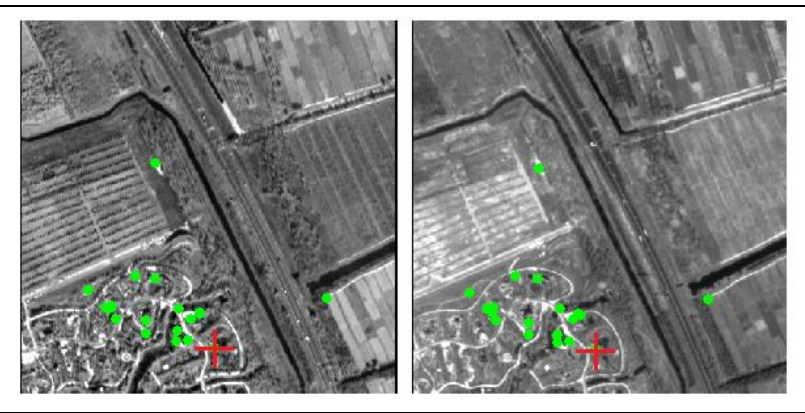

Figure 3. Tie point selection

6 ground control points and 54 tie points are selected in this experiment. The red point is the ground control point in Figure 1. The blue point is the tie point in Figure 1.

Automatic selection of tie points are through image matching in Figure 3. A total of 54 tie points are selected. 


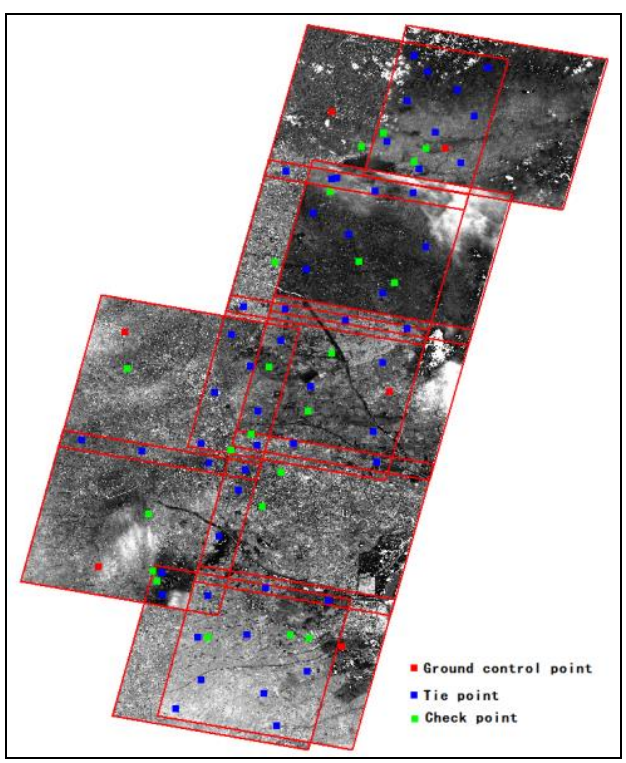

Figure 5. GCP and Tie point distribution parameters and output the orthophoto images. Overall accuracy statistics are shown in Table 1. Select corresponding points on orthophoto images and the control images.

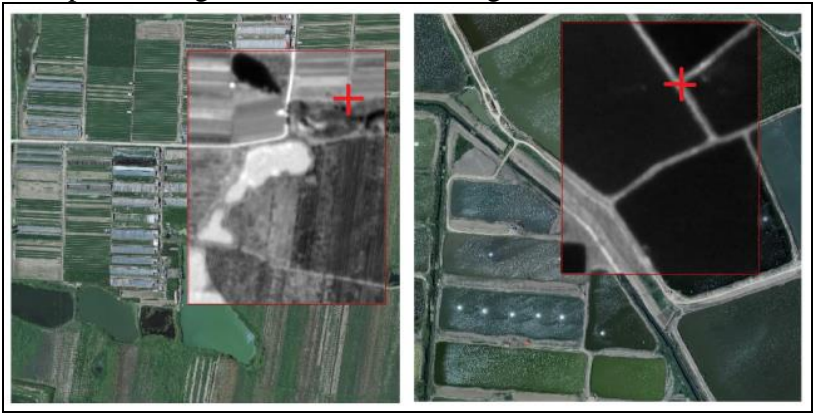

Figure 6. Check point selection

After selecting ground control points and tie points, we use linear and non-linear adjustment methods to solve model

\begin{tabular}{|l|c|c|c|c|c|c|c|c|c|}
\hline $\begin{array}{c}\text { Adjustment } \\
\text { method }\end{array}$ & Gcp & $\begin{array}{c}\text { Tie } \\
\text { Point }\end{array}$ & $\begin{array}{c}\text { Check } \\
\text { Point }\end{array}$ & $\begin{array}{c}\text { Maximum } \\
\text { column } \\
\text { error(pixels) }\end{array}$ & $\begin{array}{c}\text { Maximum } \\
\text { row } \\
\text { error(pixels) }\end{array}$ & Total(pixels) & $\begin{array}{c}\text { RMSE } \\
\text { column } \\
\text { (pixels) }\end{array}$ & $\begin{array}{c}\text { RMSE } \\
\text { row } \\
\text { (pixels) }\end{array}$ & $\begin{array}{c}\text { RMSE } \\
\text { (pixels) }\end{array}$ \\
\hline Linear & 6 & 54 & 22 & 0.88 & -0.79 & 1.18 & 0.26 & 0.27. & 0.37 \\
\hline Non-linear & 6 & 54 & 22 & 0.83 & 0.64 & 1.06 & 0.24 & 0.22 & 0.33 \\
\hline
\end{tabular}

Table 1. Precision statistics of linear and non-linear adjustment method

\subsection{Results and analysis}

The data in Table 2 is the result of accuracy statistics based on each scene image. The error distribution of the results of the two methods are similar.

In the experiment, 2 check points are selected for each view image. A total of 22 check points were selected. At the same time, object coordinates for each check point on high-precision control images were obtained.

The model location error of the check point is shown in Table 3.
RMSE of the check points is $1.436 \mathrm{~m}$, about 0.68 pixels. The result shows that the model location accuracy of the check point is high.

\begin{tabular}{|c|c|c|c|c|c|c|c|c|}
\hline Image & $\begin{array}{c}\text { Adjustment } \\
\text { method }\end{array}$ & $\begin{array}{c}\text { RMSE } \\
\text { column } \\
\text { (pixels) }\end{array}$ & $\begin{array}{c}\text { RMSE } \\
\text { Row } \\
\text { (pixels) }\end{array}$ & $\begin{array}{c}\text { RMSE } \\
\text { (pixels) }\end{array}$ & $\begin{array}{c}\text { Adjustment } \\
\text { method }\end{array}$ & $\begin{array}{c}\text { RMSE } \\
\text { column } \\
\text { (pixels) }\end{array}$ & $\begin{array}{c}\text { RMSE } \\
\text { Row } \\
\text { (pixels) }\end{array}$ & $\begin{array}{c}\text { RMSE } \\
\text { (pixels) }\end{array}$ \\
\hline 1 & Non-linear & 0.25 & 0.25 & 0.35 & Linear & 0.25 & 0.26 & 0.36 \\
\hline 2 & Non-linear & 0.2 & 0.29 & 0.35 & Linear & 0.19 & 0.3 & 0.35 \\
\hline 3 & Non-linear & 0.29 & 0.22 & 0.36 & Linear & 0.33 & 0.23 & 0.4 \\
\hline 4 & Non-linear & 0.19 & 0.2 & 0.28 & Linear & 0.19 & 0.26 & 0.33 \\
\hline 5 & Non-linear & 0.28 & 0.27 & 0.39 & Linear & 0.29 & 0.27 & 0.39 \\
\hline 6 & Non-linear & 0.33 & 0.17 & 0.37 & Linear & 0.37 & 0.2 & 0.42 \\
\hline 7 & Non-linear & 0.16 & 0.2 & 0.26 & Linear & 0.21 & 0.29 & 0.35 \\
\hline 8 & Non-linear & 0.28 & 0.26 & 0.38 & Linear & 0.26 & 0.24 & 0.35 \\
\hline 9 & Non-linear & 0.19 & 0.19 & 0.26 & Linear & 0.21 & 0.24 & 0.32 \\
\hline 10 & Non-linear & 0.17 & 0.17 & 0.23 & Linear & 0.31 & 0.37 & 0.47 \\
\hline 11 & Non-linear & 0.17 & 0.18 & 0.25 & Linear & 0.17 & 0.27 & 0.32 \\
\hline
\end{tabular}

Table 2. Accuracy of each scene image 


\begin{tabular}{|c|c|c|c|c|}
\hline Image & $\begin{array}{c}\text { Check point } \\
\text { id } \\
\end{array}$ & $\begin{array}{l}\mathrm{dx} \\
(\mathrm{m})\end{array}$ & $\begin{array}{l}d y \\
(\mathrm{~m})\end{array}$ & $\begin{array}{c}\text { RMSE } \\
(\mathrm{m})\end{array}$ \\
\hline \multirow{2}{*}{1} & Ckp_1 & -0.392 & 0.261 & 0.471 \\
\hline & Ckp_2 & -1.045 & 0.784 & 1.306 \\
\hline \multirow{2}{*}{2} & Ckp_3 & 0.392 & 0.555 & 0.680 \\
\hline & Ckp_4 & -0.588 & -0.588 & 0.831 \\
\hline \multirow{2}{*}{3} & Ckp_5 & 0.539 & 0.816 & 0.978 \\
\hline & Ckp_6 & -0.131 & -0.784 & 0.795 \\
\hline \multirow{2}{*}{4} & Ckp_7 & 1.176 & 0.914 & 1.490 \\
\hline & Ckp_8 & 1.178 & 1.437 & 1.857 \\
\hline \multirow{2}{*}{5} & Ckp_9 & -0.653 & 1.437 & 1.579 \\
\hline & Ckp_10 & 0.654 & 1.045 & 1.232 \\
\hline \multirow{2}{*}{6} & Ckp_11 & -1.437 & 0.719 & 1.607 \\
\hline & Ckp_12 & -1.306 & 1.176 & 1.758 \\
\hline \multirow{2}{*}{7} & Ckp_13 & 1.306 & 1.045 & 1.673 \\
\hline & Ckp_14 & 0.914 & 0.849 & 1.248 \\
\hline \multirow{2}{*}{8} & Ckp_15 & 1.306 & 0.784 & 1.523 \\
\hline & Ckp_16 & -1.176 & -0.392 & 1.239 \\
\hline \multirow{2}{*}{9} & Ckp_17 & -1.502 & 0.392 & 1.553 \\
\hline & Ckp_18 & -0.653 & -0.261 & 0.704 \\
\hline \multirow{2}{*}{10} & Ckp_19 & 1.208 & 0.882 & 1.496 \\
\hline & Ckp_20 & 1.209 & 1.911 & 2.261 \\
\hline \multirow{2}{*}{11} & Ckp_21 & -1.568 & 1.633 & 2.264 \\
\hline & Ckp_22 & 0.719 & 1.110 & 1.323 \\
\hline \multicolumn{5}{|c|}{ RMSE $=1.436$} \\
\hline
\end{tabular}

Table 3. Accuracy of check point(non-linear adjustment method)

\section{Conclusions}

In this paper, the linear and nonlinear block adjustment methods are used to test the data in the experimental area. Their experimental results are compared with known control image data. Test results confirm:

Under the premise of using the same control and checking data in the same area, the linear and non-linear block adjustment results have similar accuracy.

Further experiments are needed for further verify the difference between the linear and non-linear block adjustment methods. It is necessary to experiment with the data of different sensors.

\section{REFERENCES}

Tao C V, Hu Y. 2001,A comprehensive study on the rational function model for photogrammetric processn. Photogrammetric Engineering and Remote Sensing, 67 (12), pp, 1347-1357

XinmingTang,GuoZhang,XiaoyongZhu,HongboPan,YonghuaJi ang , 2012, Triple linear-array image geometry model of ZiYuan-3 surveying satellite and its validation. Acta Geodaetica Et Cartographica Sinica , 4 (1) ,pp,33-51

Toutin, Thierry, and Philip Cheng, 2000. Demystification of IKONOS,Earth Observation Magazine, 9(7),pp,17-21
Grodecki J,Dial G,2003, Block Adjustment of High-Resolution Satellite Images Described by Rational Polynomials. Photogrammetric Engineering and Remote Sensing , 69(1),pp,59-68

Dr. W. M. Häußler,1983,A local convergence analysis for the Gauss-Newton and Levenberg-Morrison-Marquardt Algorithms, Computing,31 (3),pp,231-244

Madsen K., Nielsen H.B., Tingleff O. Methods for nonlinear least squares problems.Informatics and Mathematical Modelling Technical University of Denmark. Segona edició, abril de 2004.

G. Golub and V. Pereyra, 2003, Separable Nonlinear Least Squares: The Variable Projection Method and its Applications, Inverse Problems, 19, pp,R1-R26. 